\title{
NARP syndrome
}

INSERM

\section{Source}

INSERM. (1999). Orphanet: an online rare disease and orphan drug data base. NARP syndrome. ORPHA:644

Neuropathy, Ataxia, and Retinitis Pigmentosa (NARP) syndrome is a clinically heterogeneous progressive condition characterized by a combination of proximal neurogenic muscle weakness, sensory-motor neuropathy, ataxia, and pigmentary retinopathy. 